\title{
Managing Work Systems for Complex Work via Crowdworking Platforms - How to Orchestrate the Interplay of Crowds
}

\author{
Volkmar Mrass \\ University of Kassel \\ volkmar.mrass@uni-kassel.de
}

\author{
Christoph Peters \\ University of St.Gallen \\ and University of Kassel \\ christoph.peters@unisg.ch
}

\begin{abstract}
Companies and other organizations have increasingly 'discovered' crowdsourcing as a new form how to organize their work. However, many of the platforms who manage the work system necessary to process that work focus mainly on rather simple work or work of medium complexity. Drawing on work system theory (WST) and insights from literature, in depths-case studies with 14 crowdworking platforms, a written survey among 32 platform providers and four workshops with experts from practice and research, we investigate how these crowdworking platforms can also successfully manage more complex work. Based on our analysis, we present measures to do so, classified along the core WSTelements processes and activities, participants, information, and technologies. One main measure we identified is the close gearing of external and internal crowds, fostering the advantages and mitigating the disadvantages of crowdsourcing. With our research, we aim at providing insights how to further exploit the potential of crowds.
\end{abstract}

\section{Introduction}

More than a decade after the term ,crowdsourcing“ was coined [13], a wide range of organizations are using the "wisdom of crowds" [34] to pursue their businesses and goals. In addition to volunteer-based crowdsourcing and crowdfunding, a paying industry emerged, with platforms providing access to different kinds of workers and the execution of various forms of work [17]. At the same time, governments and unions in many markets increasingly seem to notice a need for regulation in this area (see e.g. [4]). One reason for this development could be that more and more people regard such work on web-based platforms as an important source of their income [20], or even as a full-time job [10].

Although the economic importance of digital work in general [24] as well as of crowdsourcing in particular has risen, many aspects regarding crowdworking platforms have not been investigated by the IS community intensively so far. This is especially true regarding the management of work systems for complex work via such platforms. Existing contributions about crowdworking platforms from the IS area often focus on microtask-platforms with their relatively simple [18], low-paid [23] work. They also focus mostly on specific parts of the work on crowdworking platforms and do not consider the whole work system including the interplay between its parts as their unit of analysis. The little research about the management of work systems for complex work via crowdworking platforms is at odds with the fact that in general, researchers grant this novel form of work organization [25] via crowdworking platforms a huge potential (see e.g. [9]). Using crowdworking platforms can yield various benefits, since crowds are able to process work faster (e.g. because of the large number of contributors), better (e.g. due to knowledge and skills that are not available within a company) and cheaper (e.g. since payments are linked to performance). Many companies would like to make use of the potential and wisdom of crowds, but often refrain from because they do not think that crowds can handle complex issues. One reason could be the fact that there is only little knowledge how more complex work could be outsourced to the crowd ([20], [38]).

Taking into account the advancing digitization of work and society, the authors of this paper believe that there are at least three important reasons to explore how work systems for complex work can be managed via crowdworking platforms: Firstly, the technological development that will lead to increased "computerization" of jobs (see e.g. [12], [8]). This makes it also more likely that rather simple work currently performed by humans on such platforms will be automatized. Secondly, many crowdworking platforms are increasingly coming "under scrutiny" since several societal players (see e.g. [4]) have started discussions about fair working conditions, "new Taylorism" or minimum wages. Processing more complex work would allow to pay higher wages and to meet potential future requirements which might be imposed by legislators. Thirdly, this business model 
simply offers more potential for the processing of work than it is currently the case. The majority of crowdworking platforms focusses on work such as collecting data from the point of sale (POS), designing t-shirts, microtasks, testing devices and software, writing short texts, or the like. Examples of complex work processed via crowdworking platforms are rather rare ([27], [28]). Using the potential of crowdworking also for the management of more complex work such as engineering, financial services or technical support would be a natural further development of the business model of crowdworking platforms and would make them even more attractive to companies.

All reasons mentioned above serve us as a motivation to investigate how work systems for complex work can be managed via crowdworking platforms - an issue that has not been in the main focus of IS research so far. Research regarding this topic is important for the future success of crowdworking platforms as a digital innovation of the last decade. We position our research at the interface of IS and organizational theory, especially in the relatively new area of platform ecosystems. We aim at contributing to this realm and extending current knowledge by exploring measures for the successful management of work systems for complex work via crowdworking platforms. To do so, we look at this issue on a more "macro-level", using the lens of work system theory (WST) [1] and investigating the interplay of several participants as well as information and technologies to perform processes and activities with the aim to deliver products and services to the customers. We pursue the following research question:

RQ: How can work systems for complex work be managed and the interplay of crowds orchestrated successfully via crowdworking platforms?

After this introduction, this paper proceeds as follow: First, we provide a foundational theoretical background. Second, we describe the research methods and case selection. Third, we communicate our main findings regarding the management of complex work systems via crowdworking platforms, structured along the core components of the work system. Finally, we close with a discussion and a conclusion for our research.

\section{Theoretical Background}

An accurate definition of main concepts used in this paper is key to its better understanding. Therefore, we first introduce some key terms and elaborate on them: The fundamental idea of crowdsourcing is that a crowdsourcer (which could be a company, an institution or a non-profit organization) proposes to an undefined group of contributors or crowdsourcees (individuals, formal or informal teams, other companies) the voluntary undertaking of work presented in an open call [5].
Crowdsourcing platforms can be seen as intermediaries and in general the point where management of the crowd takes place. If these platforms focus on the processing of paid work (in contrast for example to platforms for fundraising or voting), we use the terms crowdworking platforms (as a subset of crowdsourcing platforms) and crowdworkers.

Drawing on de Reuver, Sørensen and Basole ([30], see among others table 1 there), these crowdworking platforms are a form of digital platforms that we classify and define along the following concepts: They are multisided platforms that mediate different groups (such as crowdworkers who process work and crowdsourcers who provide work), include indirect network externalities (the value of the platform for both the crowdworkers and the crowdsourcers depends on the number of users in the respective other group since for example a platform with only a few crowdworkers is not likely to be able to manage large amounts of provided work), can be seen from a sociotechnical platform view (i.e., include both technical elements and associated organizational processes and standards), entail an organizational ecosystem view (so not only a collection of technical complements) and show a high degree of platform openness (easy entrance and exit for both crowdworkers and crowdsourcers as well as open technical architectures such as application programming interfaces (APIs) to connect customer company systems with the platform).

In organizational environments, work is "the application of human, informational, physical, and other resources to produce products/services" [1], p. 75). Complex work is for the authors of this paper - derived from the description of characteristics of simple work on a microtask platform by Kittur et al. [18] and reversing these - in general work that mostly requires coordination, a high level of cognitive effort, expertise and skills in the respective area, time and contextual information; it is usually heterogeneous, interdependent, rather nonrepetitive and has multiple stakeholders. The World Bank uses in a study [19] skills and education or training required as a proxy to determine work complexity. It assigns low complexity to microwork where usually no specialized skills or training are required and basic computer and Internet literacy (and the associated language) skills are usually sufficient. It attributes high complexity ([19]) to work from areas such as engineering, software development or human resources. Even though the nature of the word "complex" hampers a sharp distinction, this definitions and elaborations should nevertheless provide guidance to help to better understand the characteristics of complex work.

A work system is "a system in which human participants and/or machines perform work (processes and activities) using information, technology, and other resources to produce specific products/services for specific internal and/or external customers" [1], p. 75). In 
our case, participants of the work system are first of all the crowdworkers, but often also the customers if they participate in the creation of the products and services, or the internal employees of the crowdworking platform. Information refers to informational entities such as orders or invoices as well as to conversations and verbal commitments by the work system participants [1], p.80). Technologies include both tools that are used by work system participants and automated agents (i.e. hardware and software configurations) since some work systems are totally automated (ibidem). Processes and activities occur in the work system to create products and services for its customers. Table 1 provides an overview of the work system framework (WSF) [1], p. 78) that also includes environment, infrastructure and strategies. The core work system is depicted in the shaded area. With our research, we are looking at IT-reliant work systems; more specifically, at work systems that are managed via crowdworking platforms. During our research, we noticed that the complexity of work highly correlates with the complexity of the work system to manage the processing of that work (and vice versa).

The reason why we chose the work system theory (WST) including one of its core components, the work system framework (WSF), is that it provides a very use- ful lens to analyze crowdworking platforms and the environment they are embedded in because of huge similarities between WSF and crowdworking platforms: Crowdworking platform providers have to manage participants (e.g. the crowdworkers, but also customer company employees and internal employees of the platform if they participate in the processing of the work), as well as information (e.g. about the requirements of the customer or specifics of the work that has to be processed), and technologies (e.g. tools of the electronic platform that is used). They conduct processes and activities with the aim to deliver products and services to their customers. Another main reason why work system theory (WST) is a good fit to serve as a theoretical foundation for our research is the fact that WST's domain of greatest relevance are IT-reliant work systems (see Alter [1], p. 75) to which crowdworking platforms and their environment can be counted because of the mere nature of their 'construction'. Furthermore, even though work systems are viewed as socio-technical systems, WST extends beyond the purely sociotechnical realm by covering totally automated systems ([1], p. 91) as are prevalent at several crowdworking platforms with the aim to gain efficiency advantages compared to the processing of work in 'regular' organizational/company settings.

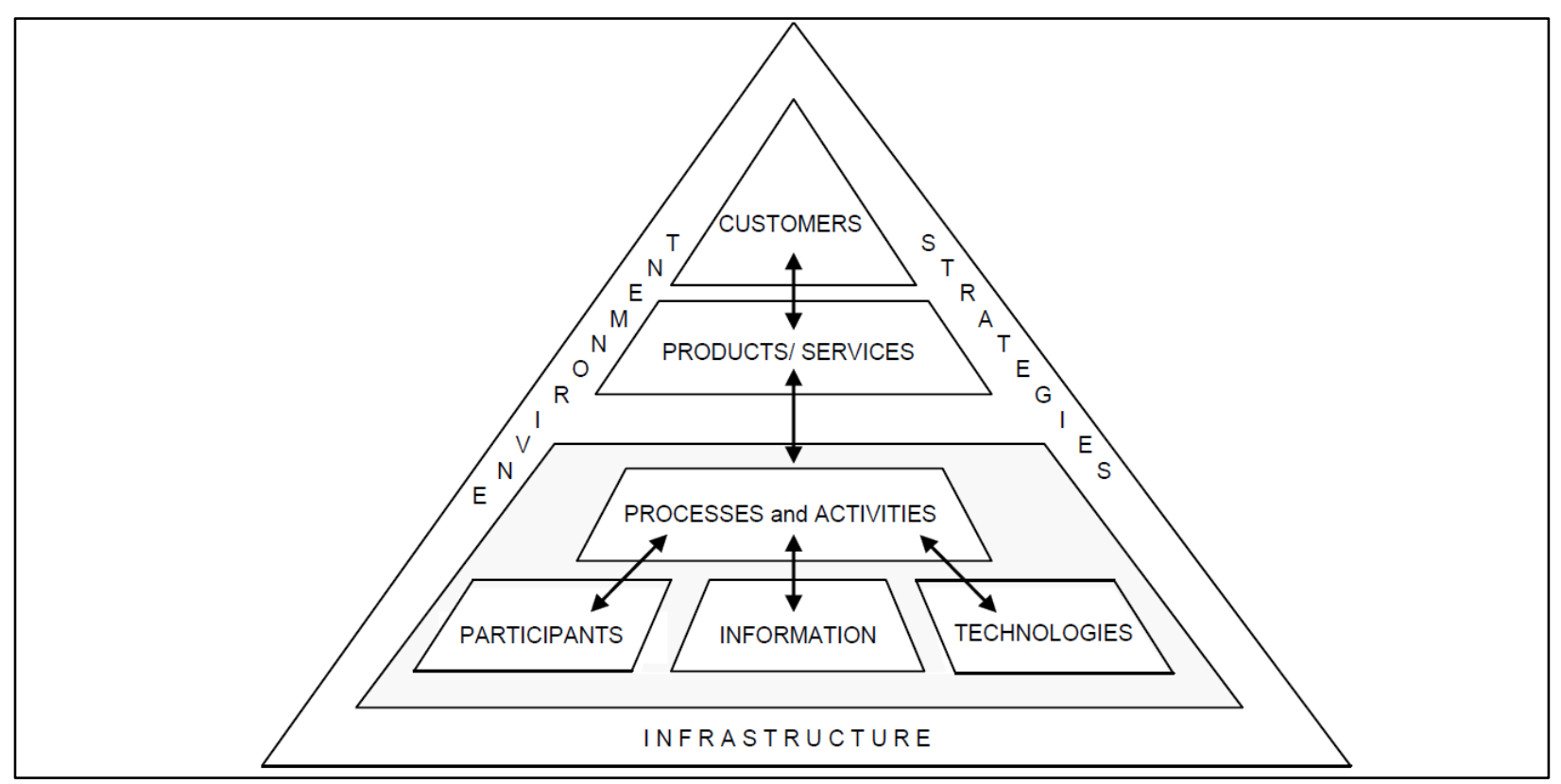

Figure 1. The Work System Framework (Alter [1], p. 78)

For the focus of our research, the field of organizational theory - both "classical" and more recent streams - offers insights on different levels as background. Scott and Davis [32] for example provide a good overview of several approaches and theories that help to connect the area of complex systems in general with complex work systems managed via crowdworking platforms. Exam- ples include Fayol's [11] top-down managerial approach to divide and coordinate complex work, Boulding's [7] classification of systems by their level of complexity, Beer's [3] classification of systems ranging from simple/deterministic over complex/ probabilistic to exceedingly complex/ probabilistic, Ashby's [2] notion that no complex system can only be understood by an attempt to decompose the system into its individual 
parts and Perrow's [29] view that with regard to complex, probabilistic systems, the whole is more than the sum of its parts. Particularly notable is also the view, communicated among others by Scott [31] and Stinchcombe [33], that one way to manage greater complexity is not to divide the work and distribute it among different workers but to tackle complexity with more highly qualified and flexible performers (professionals) and that as levels of complexity, uncertainty and interdependence increase, formerly independent professionals are likely to move their work into organizational structures. This corresponds with insights we got from case studies with 14 crowdworking platforms and in four workshops with practitioners, professional associations and researchers and led us to the proposal of closely gearing external and internal crowds/employees of a company as an important measure when it comes to the processing of complex work (see section 5 findings).

The area of platform ecosystems also provides background and insights for the management of work systems via crowdworking platforms. Boudreau et al. [6] for example assess the main requirements for successful online team collaborations outside a company. They show how alternative organizational forms such as online collaborative platforms can coordinate the collective effort of creative workers to solve complex innovation problems. The authors also point out that the history of online collaborative platforms stresses the use of enabling technologies and processes that simply reduce coordination costs. Similarly, Tiwana et al. [35]) note that information technology (IT) has yielded formerly infeasible forms of organizational governance and that these new logics have at the same time reinforced the need for effective IT governance. They identify theoretical blind spots regarding IT governance research and note that only miniscule attention has been directed to larger-scale ecosystems of firms and systems so far ([35]). This is also the area where work systems for complex work managed via crowdworking platforms as our unit of analysis can be positioned and to which we aim at contributing with our research.

\section{Research Methods and Case Selection}

As stated above, the unit of analysis of our research is the work system [1], especially its core part consisting of processes and activities, participants, information and technologies. To pursue our research question how work systems for complex work can be successfully managed via crowdworking platforms, we used insights from different sources: Literature from both the IS area and neighboring disciplines (see also section above) to gain an overview and identify relevant concepts and theories. Case studies with 14 crowdworking platforms (including 23 qualitative interviews of about 1 to $1 \frac{1}{2}$ hours with mostly platform C-level executives from May 2016 until March 2018) to investigate directly "in the field" how different kinds of platforms manage different sorts of work systems (see table 2). A written survey among 32 crowdworking platforms conducted from January to March 2017 which aimed to gain an overview over the crowdworking platform landscape and also included a question about the management of complex work via crowdworking platforms. And four workshops, conducted on March 21 ${ }^{\text {st }}$, 2017, in Munich (with experts from practice, professional associations and research), on August 31 ${ }^{\text {st }}, 2017$, in Kassel (with experts from five crowdworking platforms), on November $21^{\text {st }}, 2017$, in Munich (with experts from companies, unions and universities) and finally on April $25^{\text {th }}, 2018$, in Frankfurt (with representatives from foundations, politics, professional associations, research and unions), where we discussed and evaluated our findings.

Since they constitute the most important source for our findings, we will now elaborate in more detail how we conducted our case studies. Within the case studies in turn, in depths, semi-structured interviews have been the most important sources. All interviews have been recorded and subsequently transcribed.

With regard to the case study design, Yin [37] emphasizes five components as especially important. Table 1 depicts these components and shows how we answer them by our research design. According to him, this research method is in general especially useful when (1) the main research questions are "how" or "why" questions, (2) a researcher has little or no control over behavioral events and (3) the focus of study is a contemporary (not entirely historical) phenomenon. This is true in our case: With our research question, we strive to investigate how work systems for complex work can be managed via crowdworking platforms; we have no influence on behavioral events since we do not interfere in the interactions between crowdsourcers, platforms and crowdworkers and the focus of our study, crowdworking platforms, are a current phenomenon and not something from the past. Furthermore, Yin [37] states that case studies - like other research methods can be used for exploratory, descriptive or explanatory purposes. Our multiple case study focusses on the exploratory aspect since there is only little research about the topic of the management of work systems for complex work via crowdworking platforms so far and our aim is to shed more light on this issue.

As already mentioned, we used a multiple-case study approach, consolidating 14 single case studies with different crowdworking platforms to one embedded design. The reason for using such a design is that evidence from multiple-case studies is often considered more compelling [37]. 
Table 1. Five components of case study design and how we tackled them (based on Yin [37])

\begin{tabular}{|l|l|}
\hline Component & Approach/strategy \\
\hline Case study question & $\begin{array}{l}\text { Our research question is a "how" question as according to Yin one of the } \\
\text { two sorts of questions which are especially appropriate for case studies }\end{array}$ \\
\hline Proposition & $\begin{array}{l}\text { According to Yin [37], exploratory research does by nature usually not } \\
\text { have any propositions, but should instead nevertheless state the purpose } \\
\text { of the exploration. We aim at exploring how work systems for complex } \\
\text { work can successfully be managed via crowdworking platforms }\end{array}$ \\
\hline Unit of analysis & $\begin{array}{l}\text { We determine the core work system (processes and activities, partici- } \\
\text { pants, information and technologies) as our unit of analysis. Boundaries } \\
\text { are set by focusing on platforms with headquarters or at least a (physical) } \\
\text { location in Germany since a worldwide view is infeasible and since at the } \\
\text { same time, these platforms allow a sufficient generalization of findings }\end{array}$ \\
\hline $\begin{array}{l}\text { Logic linking the data to the } \\
\text { propositions }\end{array}$ & $\begin{array}{l}\text { The linking of data to the purpose (not proposition/see above) is done by } \\
\text { the techniques of cross-case synthesis + pattern matching }\end{array}$ \\
\hline $\begin{array}{l}\text { Criteria for interpreting the } \\
\text { findings }\end{array}$ & $\begin{array}{l}\text { We use the strategy to identify, address, investigate and (if appropriate) } \\
\text { reject rival explanations for our findings }\end{array}$ \\
\hline
\end{tabular}

For the selection of the cases, we used the following criteria to be able to generate the desired insights corresponding to the research question communicated above: We selected 14 crowdworking platforms that include different archetypes and characteristics and provide different kinds of services. This allows us to investigate the issue of the management of work systems for complex work via crowdworking platforms in various settings and from different perspectives to back the validity of the findings. The selected platforms already exist for a while and have a stable business record, making it more likely that they have gained enough expertise to answer our research question adequately. Even though the platforms are from a specific region (Germany/Europe), they are positioned on an international basis and therefore ease comparability and the application of the findings. Using the criteria mentioned above, we selected the following crowdworking platform companies and among others conducted 1 to $1 \frac{1 / 2}{2}$-hours lasting interviews with them (in parts also with their customers or other stakeholders such as owners):

Table 2. Fourteen selected crowdworking platforms and main interview partners (own depiction)

\begin{tabular}{|l|l|l|l|l|}
\hline Platform & Headq./Location & Services & Main interview partner & Interview Date \\
\hline Across & Karlsbad/Germany & Marketplace & Chief Sales Officer & June $7^{\text {th }}, 2016$ \\
\hline Crowd Guru & Berlin/Germany & Microtasking & Chief Executive Officer & July $6^{\text {th }}, 2016$ \\
\hline Jovoto & Berlin/Germany & $\begin{array}{l}\text { Design/Inno- } \\
\text { vation }\end{array}$ & Chief Executive Officer & $\begin{array}{l}\text { July } 19^{\text {th }}, 2016 \\
+ \text { June } 1^{\text {st }}, 2017\end{array}$ \\
\hline Testbirds & Munich/Germany & Testing & Chief Operating Officer & July $21^{\text {st }, 2016}$ \\
\hline Passbrains & Rapperswil/Switz. & Testing & Chief Executive Officer & August $9^{\text {th }, 2016}$ \\
\hline Clickworker & Essen/Germany & Microtasking & Marketing Manager & September $26^{\text {th }}, 2016$ \\
\hline Content.de & Herford/Germany & Content/Text & Chief Executive Officer & September $27^{\text {th }, 2016}$ \\
\hline Innosabi & Munich/Germany & Innovation & Managing Director & September $28^{\text {th }}, 2016$ \\
\hline Twago & Berlin/Germany & Marketplace & Chief Executive Officer & September $28^{\text {th }}, 2016$ \\
\hline TestlO & Berlin/Germany & Testing & Chief Executive Officer & September $30^{\text {th }, 2016}$ \\
\hline Mila & Zurich/Switzerland & Sales & Chief Executive Officer & January $27^{\text {th }, 2017}$ \\
\hline Phantominds & Hamburg/Germany & Innovation & Managing Director & $\begin{array}{l}\text { February } 21^{\text {st }}, 2017 \\
+ \text { June } 13^{\text {th }}, 2017\end{array}$ \\
\hline Hyve & Munich/Germany & Innovation & $\begin{array}{l}\text { Managing Director }+ \\
\text { Senior Consultant }\end{array}$ & $\begin{array}{l}\text { May } 31^{\text {st }}, 2017 \\
+ \text { July } 5^{\text {th }}, 2017\end{array}$ \\
\hline Local Motors & Berlin/Germany & Engineering & Manager & $\begin{array}{l}\text { July } 11^{\text {th }}, 2017 \\
+ \text { March } 16^{\text {th }}, 2018\end{array}$ \\
\hline
\end{tabular}


Besides these main interviews with $\mathrm{C}$-level executives from crowdworking platforms, we also conducted interviews with representatives of customer companies (e.g. one with the chairperson of the works council of a customer company (on June $6^{\text {th }}, 2016$ ), one with the Head of Customer Service of Mila's main customer and owner Swisscom (on February $14^{\text {th }} .2017$ ), or one with the Head of UAV Portfolio and Innovation at the Local Motors customer company Airbus Defense and Space (on December $4^{\text {th }} .2017$ ). In addition, we also conducted an interview with the president of a former crowdworking platform that has switched its business model (on November $15^{\text {th }}, 2016$ ) or with independent experts (such from Deutsche Flugsicherung on March $29^{\text {th }}, 2018$ ) to also gain insights from these perspectives.

Regarding data analysis, we initially followed recommendations from Mayring [21] for qualitative content analysis to derive our findings from the transcripts of the interviews, even though we did not pursue this approach in every detail. We deeply immersed into every interview transcript and checked for every sentence if, and if yes, what conclusions for the management of work systems for complex work via crowdworking platforms could be drawn from it. For example, when a crowdworking platform CEO reported that assuring proper education and skills of the crowdworkers is one main success factor to process complex work via their platform (since crowdworkers are by nature of this novel form of work organization not as well-known to the platform provider as 'regular' employees are to a company), we put this finding into the category that relates to "participants" and communicated it there. We organized the findings according the structure of the work system framework (see above).

\section{Findings}

In this section, we depict our main findings, structured along the core work system elements processes and activities, participants, information and technologies (see figure 1). Even though some of these measures are naturally also applicable to simple work or work of medium complexity, they represent measures that are especially important when it comes to the management of work systems for complex work.

Processes and activities. Our research showed two main approaches to tackle complex work via crowdworking platforms in practice. On the one hand the approach to divide work into a set of smaller tasks, to process those tasks by different crowdworkers and to later reassemble them by the platform operator to the initial larger work. We encountered this approach mainly at microtask platforms. „If work is complex, we strive to divide it into many smaller tasks. One reason is that the result is better at the end if a crowdworker can concentrate on one smaller, single task. Then we reassemble everything and deliver it to the customer" (CEO of a microtask crowdworking platform). Another approach is to tackle work jointly, with each crowd worker having "the full picture", processing work by mutual coordination and cooperation. We encountered this approach at innovation platforms. ,We have realized that the more humans are working together, the more different perspectives evolve and the better the solutions for complex work are" (CEO of an innovation crowdworking platform). Another key issue is the proper structuring of work. The more complex work is, the more imperative is it to properly communicate and precisely structure it to ensure a successful completion. There is also the need for a clear specification of the solution format that has to be delivered. Finally, crowdworking platforms have to take quality assurance measures for the completed work, conducted for example either by internal employees of the platform provider or (other) external crowd workers. For further details on the potential of gearing external and internal crowds, see the next section.

Participants. One key success factor for crowdworking platforms to manage work systems for complex work concerning the participants is to invest continuously in keeping a crowd that is large enough, motivated and has the required functional qualifications. Unlike "classical" organizations such as companies, there are few obligations for participants on both sides. Crowdworkers can decide if and when to process work offered via crowdworking platforms on a daily basis. The same is true for the crowdsourcer/customer since companies also might switch to other crowdworking platforms if they are not satisfied with the results (platform openness with easy entrance and exit for both crowdworkers and crowdsourcers, see also [30]). Or as several of our interview partners put it, it is important "to manage both the demand and supply-side equally": If there are many crowdworkers and only few work, the former will quit. If there is plenty of work but a crowd not large or qualified enough to complete it, the latter will do. Crowdworking platforms have to balance these two groups.

Incentives for the crowdworkers to participate in the respective work system such as monetary rewards or reputational ones (e.g. badgets or rankings based on work successfully completed or the degree of participation), are also very important when it comes to win participants to process complex work. Some crowdworking platforms furthermore invest in CI measures to foster a shared identity of the participants of the work system. One example is the testing platform "Testbirds" that labels their crowdworkers "birds", their e-learning tools "bird school" and the platform itself the "nest". Such measures help to keep workers with the platform and therefore support the management of work systems for 
complex work. Our findings from the case studies suggest that the most important measure when it comes to the successful management of work systems for complex work is the close gearing of external and internal crowds/employees of a customer company through one crowdworking platform in order to utilize both the knowledge of external and internal experts (see also [26]). The more complex work is, the more beneficial this approach is since it ensures that the solution is not only 'state-of-the-art', but also considers specifics of the respective customer company. It also helps to exploit the advantages and mitigate the disadvantages of crowdworking. There are several variants for this gearing: For example,

- Companies who have processed work via external crowds on a crowdworking platform can let their internal crowds/employees evaluate this work, e.g. to check its feasibility, quality or fit with special organizational requirements

- $\quad$ internal crowds/employees of a company identify important challenges or problems that could not been solved within the company and which are subsequently given to the external crowd via an open call on a crowdworking platform
- During a project that a company processes via a crowdworking platform and an external crowd, internal crowds/employees of this company can be assigned to give the external crowd continuous feedback, ensuring that the work goes 'in the right direction' and the companies' expectations are met

- The detailed briefing of external crowds at the beginning of a cooperation/project can also be done by an internal crowd, helping to achieve good results especially when it comes to complex work

- And finally, another variant is that work is first 'offered' to the internal crowd/employees via an open call on a crowdworking platform. If the respective work is not taken internally after a certain amount of time (e.g. after two days), this work is automatically routed to an external crowd. This approach allows to both 'use' an external crowd 'on demand', especially in peak times when internal crowds are not available due to high workload, illness, vacation, or the like, and to bring in external knowledge if the internal crowd did not take that work because of lack of knowledge necessary to process it. Figure 2 shows a schematic overview of the gearing of external and internal crowds/employees.

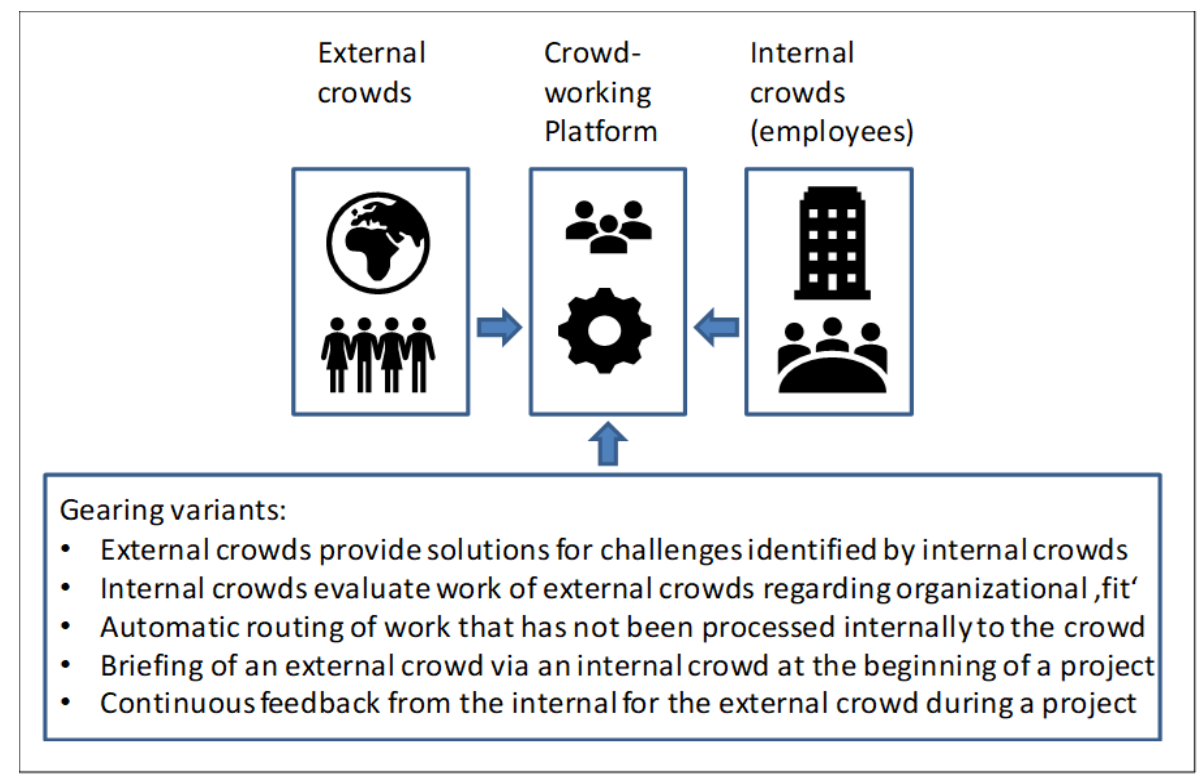

Figure 2: Gearing of External and Internal Crowds/Employees (own depiction)

The Chief Sales Officer of a marketplace crowdworking platform: "Yes, we think that crowdworking platforms will also increasingly be used for more complex work. Being able to combine internal and external knowledge here is a clear advantage. Connecting external and internal crowds via one platform also gives the respective company advantages regarding flexibility and speed."
Another main key factor we found when it comes to the management of work systems for complex work via crowdworking platforms are the education and skills of the participants. This is also in accordance with literature (see e.g. [31] and [33] that one way to manage greater complexity is to tackle complexity with more highly qualified and flexible performers (professionals)). This statement is not only true compared to simple or medium complex work processed via crowdworking 
platforms, but also compared to work processed within companies. Our research showed that education and skills are way more important than in the 'normal' job world since differences with regard to these characteristics are high given the heterogeneity of the crowd compared to employees of a company who are more likely to be selected according to uniform criteria. We found evidence that many crowdworking platforms are aware of this critical success factor and that they are heavily investing in keeping the best qualified crowdworkers on their platforms. Measures include among others assessment centers, qualification tests or e-learning tools. „The most important thing is the qualification of the crowd, their professionalism. We are investing in this realm. We have an assessment center on our platform to be able to judge the qualification of a crowdworker before we assign certain jobs. With our assessments, we ensure to engage the right people for a given project and to deliver good results when processing complex work" (CEO of a testing crowdworking platform). Regarding the customers who often also are direct participants in the work system, trust also seems to be paramount. Especially since companies often assume that highly complex work is still better managed by internal employees. „One major prerequisite for the processing of complex work is the trust of your customers. You have to imagine: A company uses a crowdworking platform for the first time. If that works, the company gets more confident and outsources more complex work. If this works, too, they outsource even more complex work to the crowd, and so on" (CEO of a testing platform).

Information. Unlike in "traditional" work settings, crowdworkers do not necessarily have (regular) contact to each other. Platforms have to take measures to foster the communication of information necessary to manage work systems for complex work. The more complex work is, the more important is the opportunity also for "direct communication" between company, platform and crowd worker. We found that some crowdworking platforms account for this even with measures from the "non-virtual, physical world" such as on side workshops with selected members of the crowd and customers. Many crowdworking platforms employ own "community management" departments that coordinate und distribute information or assign this function to longstanding, selected crowdworkers. This also includes information when work has not been done to the satisfaction of the customer. We found interesting in this context that some platforms even pay crowdworkers for processed work if the result does not meet the expectations of the customer and the platform therefore has to reassign the work to other crowdworkers (and has to "pay twice"), just to avoid atmospheric disturbances. Another important point is an attractive communication of the respective work via the platform to gain a broad variety of potentially innovative crowdworkers from different backgrounds in the first place since this leads to better results. „Humans who are processing work on crowdworking platforms are social beings with needs, wishes, fury, joy and other emotions. They have to be 'managed', somebody has to moderate. This is an important factor if one wants to increase the performance, especially with regard to complex work" (CEO of an innovation crowdworking platform). Another important point from the findings of our research is to secure the confidentiality of company information and to make arrangements with regard to legal issues. The open nature of work systems managed via crowdworking platforms entails the risk of legal issues, for example from the realm of intellectual property/patents.

Technologies. Especially regarding complex work, communication and collaboration between all parties (crowdsourcer, crowdworking platform, crowdworker) must also be enabled from the technological side. Technology should for example allow to preselect certain crowdworkers based on skills, performance or work record. It needs interfaces to include external a $\mathrm{n} d$ internal crowds to better handle complexity and even allow companies to include specific crowds consisting of their own customers or suppliers ("bring your own crowd"). Crowdworking platforms have to make sure that their technology is adaptive to the trend of increasingly softening borders of organizations. In addition, the proper definition and management of the interfaces, especially to the customers, is paramount when it comes to manage complex work and the respective systems. ,The interface between crowdworkers, platform and customers is a key aspect. To engage all parts of the 'supply chain', to connect them, to equip them with the respective data and to incorporate quality assurance measures is important" (Chief Sales Officer of a marketplace crowdworking platform). In congruence with literature on platform boundary resources (see e.g. [14]) and taking into account the above mentioned trend of softening company borders, one key aspect in this context is also the provision of suitable APIs.

\section{Discussion and Conclusion}

Using insights from literature, case studies, a written survey and workshops, we investigate how work systems for complex work can be managed via crowdworking platforms. One main difference to work processed within "regular" company settings or even via other kinds of online platforms that has to be taken into account is the aspect of self-selection. Work is usually not directly assigned to a specific employee within a company or outsourced to a specific worker on a platform, but to a crowd of potential contributors. Since the latter can decide case-by-case if they participate in the work 
system, different management measures apply. With regard to the management of work systems for complex work via crowdworking platforms, some of the most important measures we found with our research are to enable the gearing of different participants of the respective work system (especially external and internal crowds/employees), assessments that ensure the required qualifications of the (often unknown) crowdworkers since education and skills are an important way to tackle complexity and a clear communication and specification of the work goals since contextualization similar to those in "regular" organizations is often lacking. Furthermore, motivational measures to continuously keep a heterogenous and highly skilled crowd that is able to tackle complex work and an efficient technological landscape that is adaptive to the trend of increasingly softening borders of organizations and at the same time allows automatization (where possible) to reduce coordination costs. And finally, measures to ensure the protection of intellectual property since sensible information is more likely to occur within work systems for complex work and is more difficult to protect in open platform work systems.

Current literature from IS, organization theory as well as platform ecosystems, does not focus very much on the management of work systems for complex work via crowdworking platforms. Exceptions include

- $\quad$ Kittur et al.'s contributions (see [18], [16] and [17]) that deal more with complex tasks (in the sense of rather smaller parts of work) than complex work, but nevertheless offer some interesting insights. They a) provide a web-based general purpose framework prototype for accomplishing complex and interdependent tasks using micro-task markets ('CrowdForge'), b) a workflow management interface ('CrowdWeaver') for the management of complex tasks via a visual interface and c) a framework that shall enable crowd work that is complex

- Morishima et al. [22] who present a declarative platform for complex data-centric crowdsourcing ('CyLog/Crowd4U'), equipped with a suite of tools for rapid development of applications and

- Valentine et al. [36] who propose a technical tool ('Foundry') that helps to create what they call "flash organizations": The structuring of crowds like organizations, including roles, teams and hierarchies, with the aim to enable complex and openended goals respectively work. The tool allows the automated hiring of crowds from crowdworking platforms such as Upwork and the adaptive coordination of them.

In contrast to these contributions that are rather 'technical tool-oriented' and provide a technical solution (for example a kind of 'meta-tool' that connects to crowdworking platforms and allows to post work on them but is not operated by them), we aim at providing insights for the whole work system. Our research aims at contributing to the area of digital platforms and at shedding more light on an underexplored new form of work organization enabled by crowdworking platforms. This is important not least given the increasing trend of the platformization of digital goods and services [15].

With our findings, we aim at contributing to both practice and research: Companies who plan to process complex work via crowdworking platforms and platform providers who manage the respective work systems gain insights what measures must be taken to do so. Since much work currently managed via crowdworking platforms is of rather simple or medium complexity, these insights can enlarge the spectrum of work processed via crowdworking platforms and increase their potential. For researchers, especially in the realm of IS, organizational theory and platform ecosystems, we likewise provide research insights/stimuli and pave the way for future research in this important realm of crowdworking platforms and digital platforms.

\section{Acknowledgements}

This paper presents research that was conducted in the context of the project "Challenge cloud and crowd" that is funded by the German Federal Ministry of Education and Research (BMBF) within the program "Innovations for Tomorrow's Production, Services, and Work" (funding number: 02K14A071) and managed by the Project Management Agency Karlsruhe (PTKA).

\section{References}

[1] Alter, S. 2013. Work System Theory: Overview of Core Concepts, Extensions, and Challenges for the $\mathrm{Fu}-$ ture. Journal of the Association for Information Systems (JAIS) 14, 2, 72-121.

[2] Ashby, W. R. 1956. The Effect of Experience on a Determinate Dynamic System. Behavioral Science 1, 1, 35-42.

[3] Beer, S. 1967. Cybernetics and Management. John Wiley, New York.

[4] Benner, C., Ed. 2014. Crowdwork - zurück in die Zukunft? Perspektiven digitaler Arbeit. Bund-Verlag $\mathrm{GmbH}$, Frankfurt am Main.

[5] Blohm, I., Leimeister, J. M., and Krcmar, H. 2013. Crowdsourcing: How to Benefit from (Too) Many Great Ideas. MIS Quarterly Executive 12, 4, 199-211.

[6] Boudreau, K., Gaule, P., Lakhani, K. R., Riedl, C., and Williams Woolley, A. 2014. From Crowds to Collaborators: Initiating Effort \& Catalyzing Interactions Among Online Creative Workers. Working Paper 14060. Harvard Business School.

[7] Boulding, K. E. 1956. General Systems Theory-The Skeleton of Science. Management Science 2, 3, 197208. 
[8] Brynjolfsson, E. and McAfee, A. 2011. Race against the machine. How the digital revolution is accelerating innovation, driving productivity, and irreversibly transforming employment and the economy. Digital Frontier Press, Lexington, Mass.

[9] Colombo, G. and Buganza, T. 2013. Crowdsourcing intermediaries and problem typologies: An explorative study. International Journal of Innovation Management 17, 2.

[10] Deng, X. (N.) and Joshi, K. D. 2013. Is Crowdsourcing a Source of Worker Empowerment or Exploitation? Understanding Crowd Workers' Perceptions of Crowdsourcing Career. Proceedings of the International Conference on Information Systems (ICIS) 2013.

[11] Fayol, H. 1949. General and Industrial Management. Pitman, London.

[12] Frey, C. B. and Osborne, M. A. 2013. The Future of Employment: How Susceptible are Jobs to Computerisation? Oxford Martin School Publications.

[13] Howe, J. 2006. The Rise of Crowdsourcing. Wired Magazine 14, 6, 176-183.

[14] Huhtamäki, J., Basole, R. C., Still, K., Russell, M. G., and Seppänen, M. 2017. Visualizing the Geography of Platform Boundary Resources:. The Case of the Global API Ecosystem. 50th Hawaii International Conference on System Sciences (HICSS), Waikoloa, USA, 53055314.

[15] Kazan, E., Tan, C.-W., Lim, E. T.K., Sørensen, C., and Damsgaard, J. 2018. Disentangling Digital Platform Competition. The Case of UK Mobile Payment Platforms. Journal of Management Information Systems (JMIS) 35, 1, 180-219.

[16] Kittur, A., Khamkar, S., André, P., and Kraut, R. E. 2012. CrowdWeaver: Visually Managing Complex Crowd Work. Compilation publication of CSCW'12 proceedings \& CSCW'12 companion: February 11-15, 2012 Seattle, Washington, USA.

[17] Kittur, A., Nickerson, J. V., Bernstein, M. S., Gerber, E. M., Shaw, A., Zimmerman, J., Lease, M., and Horton, J. J., Eds. 2013. The Future of Crowd Work. ACM, San Antonio, Texas, USA.

[18] Kittur, A., Smus, B., Khamkar, S., and Kraut, R. E. 2011. CrowdForge: Crowdsourcing Complex Work. Proceedings of the 24th annual ACM Symposium on User Interface Software and Technology: October 1619, 2011, Santa Barbara, CA/USA.

[19] Kuek, S. C., Paradi-Guilford, C. M., Fayomi, T., Imaizumi, S., and Ipeirotis, P. 2015. The Global Opportunity in Online Outsourcing. The World Bank, Washington.

[20] Leimeister, J. M. and Zogaj, S. 2013. Neue Arbeitsorganisation durch Crowdsourcing. Eine Literaturstudie. Arbeitspapier 287, Düsseldorf.

[21] Mayring, P. 2015. Qualitative Inhaltsanalyse. Grundlagen und Techniken. Beltz, Weinheim, Basel.

[22] Morishima, A., Shinagawa, N., Mitsuishi, T., Aoki, H., and Fukusumi, S. 2012. Cylog/crowd4u: a declarative platform for complex data-centric crowdsourcing. Proceedings of the VLDB Endowment 5, 12, 1918-1921.

[23] Moussawi, S. and Koufaris, M. 2015. Working on Low-Paid Micro-Task Crowdsourcing Platforms: An Existence, Relatedness and Growth View. Proceedings of the International Conference on Information Systems (ICIS) 2015.

[24] Mrass, V., Li, M. M., and Peters, C. 2017. Towards a Taxonomy of Digital Work. 25. European Conference on Information Systems (ECIS), Guimarães, Portugal, 2017, 2515-2524.

[25] Mrass, V., Peters, C., and Leimeister, J. M. 2016. New Work Organization through Crowdworking Platforms. A Case Study. Konferenz "Zukunftsprojekt Arbeitswelt 4.0", 19.09.2016, Stuttgart.

[26] Mrass, V., Peters, C., and Leimeister, J. M. 2017. One for All? Managing External and Internal Crowds through a Single Platform - A Case Study. 50th Hawaii International Conference on System Sciences (HICSS), Waikoloa, USA, 4324-4333.

[27] Mrass, V., Peters, C., and Leimeister, J. M. 2018. Managing Complex Work Systems via Crowdworking Platforms: How Deutsche Bank Explores AI Trends and the Future of Banking with Jovoto. 51th Hawaii International Conference on System Sciences (HICSS), Waikoloa, USA, 3391-3400.

[28] Mrass, V., Peters, C., and Leimeister, J. M. 2018. Managing Complex Work Systems via Crowdworking Platforms: The Case of Hamburger Hochbahn and Phantominds. 51th Hawaii International Conference on System Sciences (HICSS), Waikoloa, USA, 4112-4121.

[29] Perrow, C. 1982. Three Mile Island: A Normal Accident. The international yearbook of organization studies, 1-25.

[30] Reuver, M. de, Sørensen, C., and Basole, R. C. 2018. The digital platform:. a research agenda. Journal of Information Technology (JIT) 33, 2, 124-135.

[31] Scott, W. R. 1966. Professionals in Bureaucracies - Areas of Conflict. Professionalization, 265-275.

[32] Scott, W. R. and Davis, G. F. 2016. Organizations and organizing. Rational, natural, and open systems perspectives. Routledge, London, New York.

[33] Stinchcombe, A. L. 1990. Information and Organizations. University of California Press, Berkeley.

[34] Surowiecki, J. 2004. The wisdom of crowds. Why the many are smarter than the few and how collective wisdom shapes business, economies, societies, and nations. Doubleday, New York.

[35] Tiwana, A., Konsynski, B., and Venkatraman, N. 2013. Special Issue. Information Technology and Organizational Governance: The IT Governance Cube. Journal of Management Information Systems (JMIS) 30, 3, 7-12.

[36] Valentine, M. A., Retelny, D., To, A., Rahmati, N., Doshi, T., and Bernstein, M. S. 2017. Flash Organizations: Crowdsourcing Complex Work by Structuring Crowds As Organizations. CHI '17 Proceedings of the 2017 CHI Conference on Human Factors in Computing Systems, 3523-3537.

[37] Yin, R. K. 2014. Case Study Research. Design and Methods. SAGE Publications, Inc., Los Angeles.

[38] Zhang, H., Law, E., Miller, R. C., Gajos, K. Z., Parkes, D. C., and Horvitz, E. 2012. Human Computation Tasks with Global Constraints. Proceedings of the SIGCHI Conference on Human Factors in Computing Systems. 